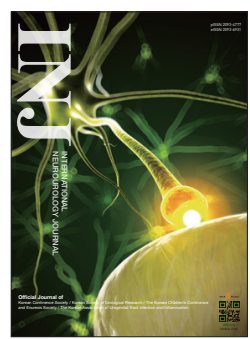

\title{
Broaden and Build Up Knowledge Based on Investigative and Clinical Research
}

\author{
Khae Hawn Kim (BD http://orcid.org/0000-0002-7045-8004 \\ Associate Editor \\ Department of Urology, Gachon University Gil Hospital, Gachon University of Medicine and Science, Incheon, Korea \\ E-mail: kimcho99@gilhospital.com
}

Medicines are improved based on the findings of various investigative and clinical studies conducted to discover the mechanisms of diseases and new treatment methods. In investigative research about diseases such as underactive bladder (UAB), even minute details are important because they can contribute to the development of new treatment.

Neurogenic lower urinary tract dysfunction is a common problem among patients with neurological disorders. According to how it manifests, it can be classified into 3 categories: (1) inability to void the bladder successfully, (2) inability to store urine adequately, and (3) a combination of both.

Several anticholinergic drugs, such as propiverine, solifenacin, imidafenacin, tolterodine, and fesoterodine, are used to improve bladder compliance and decrease detrusor overactivity (DO). However, the extensive investigative and clinical research that has been conducted recently to understand the pathophysiological mechanism of DO has revealed the effectiveness of other pharmacological compounds such as mirabegron, a novel $\beta 3$ adrenoceptor agonist, and botulinum toxin [1]. Evidence of the efficacy and safety of intravesical onabotulinum toxin A injections has led to their approval in many countries, including Korea, for the treatment of urinary incontinence due to neurogenic DO resulting from spinal cord injury or multiple sclerosis in patients refractory or intolerant to anticholinergic medications or mirabegron [2]. We can conclude from this that various therapeutic options are available for DO. However, by contrast, no effective treatments have been developed for detrusor underactivity (DU) thus far, and a paucity of research exists on this field.
The International Continence Society defines DU as "detrusor contraction of reduced strength and/or duration, resulting in prolonged bladder emptying and/or failure to achieve complete bladder emptying within a normal time span" [3]. UAB is a multifactorial and complex problem that could be classified as a neurogenic, myogenic, or idiopathic disorder based the suspected causes and underlying diseases associated with it [4]. Hoag and Gani [5] reported that the most common treatment of UAB is intermittent self-catheterization (54.4\%), followed by observation/conservative treatment (25.3\%) and sacral neuromodulation (12.7\%).

Unfortunately, accurate diagnosis and proper management of UAB are frequently encountered difficulties, even by urology experts, because of the complexity of the underlying etiology and the scarcity of treatment options. Therefore, much research is needed to better understand $\mathrm{UAB}$ and establish optimal management strategies for patients with voiding problems that affect their quality of life.

In the present issue of the International Neurourology Journal (INJ), 2 interesting articles associated with UAB were included. The first article, titled "Structural Changes of the Urinary Bladder after Chronic Complete Spinal Cord Injury in Minipigs," revealed that chronic spinal cord injury (SCI) changes the composition of the proteins in the urinary bladder wall, which leads to a reduction in the contractile and elastic properties of the bladder [6]. It demonstrated in detail how SCI severely influences the urinary bladder wall composition and depicted the similarities between minipigs and humans. The results of this 
study provide important information required for the basic understanding of the pathophysiological mechanism of UAB.

The second article, titled "Ketanserin and Naftopidil Enhance the Potentiating Effect of Alpha-Methyl-Serotonin on the Neurally-Induced Contraction of Human Isolated Urinary Bladder Muscle Strips," demonstrated that a-methyl-serotonininduced potentiation of the contraction of neurally evoked human detrusor strips was not mediated by the 5-hydroxytryptamine receptor subtypes, and was enhanced by ketanserin and naftopidil [7]. The underlying mechanism for this enhancement is still unknown. However, this study suggests that these two drugs, ketanserin and naftopidil, may be effective for treating diseases characterized by detrusor contractile dysfunction such as UAB.

The research conducted in these 2 studies should be continued and extended for better comprehensive understanding of $\mathrm{UAB}$ and for the development of suitable therapeutic strategies such as those available for DO.

The original indication of a drug can be changed and expanded by investigative and clinical studies. However, urological clinicians should avoid hasty generalizations based on findings from inadequate studies. In this regard, the article titled "Evidence Is Enough?: A Systematic Review and Network Meta-Analysis of the Efficacy of Tamsulosin $0.2 \mathrm{mg}$ and Tamsulosin $0.4 \mathrm{mg}$ as an Initial Therapeutic Dose in Asian Benign Prostatic Hyperplasia Patients" is introduced in this issue [8].

Tamsulosin is the most commonly used $\alpha$-blocker for the treatment of lower urinary tract symptom (LUTS) induced by benign prostatic hyperplasia (BPH). At the development process of tamsulosin, the initial standard dose was decided considering the difference in body mass index between Asian and Western men. Therefore, the initial standard dose of tamsulosin was introduced to patients with $\mathrm{BPH}$ was $0.2 \mathrm{mg}$ for Asian men and $0.4 \mathrm{mg}$ for Western men $[9,10]$. The degrees of improvements in international prostate symptom score and maximal flow rate were similar between Asian patients with BPH treated with tamsulosin $0.2 \mathrm{mg}$ and Western patients with $\mathrm{BPH}$ treatmed with tamsulosin $0.4 \mathrm{mg}[11,12]$. In addition, no significant adverse events were found in the patients in both groups. However, some investigators reported that ejaculatory problems were less observed in the Asian patients having $\mathrm{BPH}$ treated with tamsulosin $0.2 \mathrm{mg}$ that in the Western patients with $\mathrm{BPH}$ treated with tamsulosin $0.4 \mathrm{mg}$ [13].

Recently, a randomized controlled trial (RCT) was conducted to introduce a better treatment effect of tamsulosin $0.4 \mathrm{mg}$ as an initial dose for Korean patients with BPH than tamsulosin $0.2 \mathrm{mg}$ [14]. In general, tamsulosin $0.4 \mathrm{mg}$ is considered for Asian patients with BPH who do not show improvement of LUTS after treatment with tamsulosin $0.2 \mathrm{mg}$ as the initial standard dose. However, the results reported by Kim et al. [14] do not meet the standard consensus of tamsulosin treatment in Asian patients with BPH. Therefore, reassessment is necessary before we accept and apply the report by Kim et al. [14] in clinical practice.

The article in this issue of INJ compared the efficacy between tamsulosin 0.2 and $0.4 \mathrm{mg}$ as initial doses by using an analytical method with indirect and mixed treatment comparisons due to lack of a head-to-head direct comparison study [8]. No significant differences were found between treatment with tamsulosin 0.2 and $0.4 \mathrm{mg}$. Therefore, evidence that supported better efficacy of tamsulosin $0.4 \mathrm{mg}$ was not found from the results of a network meta-analysis. Moreover, the inconsistency between the study by Kim et al. [14] and other previous RCTs observed from the analysis also supports the fact that evidence for better efficacy of tamsulosin $0.4 \mathrm{mg}$ is lacking. Therefore, tamsulosin $0.2 \mathrm{mg}$ is still the standard initial dose for Asian patients with $\mathrm{BPH}$. Moreover, the article reflects the need to discriminate a good-quality study before application in real life.

- Conflict of Interest: No potential conflict of interest relevant to this article was reported.

\section{REFERENCES}

1. Andersson KE. On the site and mechanism of action of $\beta 3$ adrenoceptor agonists in the bladder. Int Neurourol J 2017;21:6-11.

2. Cho YS, Kim KH. Botulinum toxin in spinal cord injury patients with neurogenic detrusor overactivity. J Exerc Rehabil 2016;12:62431.

3. Abrams P, Cardozo L, Fall M, Griffiths D, Rosier P, Ulmsten U, et al. The standardisation of terminology of lower urinary tract function: report from the Standardisation Sub-committee of the International Continence Society. Neurourol Urodyn 2002;21:167-78.

4. Dewulf K, Abraham N, Lamb LE, Griebling TL, Yoshimura N, Tyagi $\mathrm{P}$, et al. Addressing challenges in underactive bladder: recommendations and insights from the Congress on Underactive Bladder (CURE-UAB). Int Urol Nephrol 2017 Feb 23 [Epub]. https:// doi.org/10.1007/s11255-017-1549-3.

5. Hoag N, Gani J. Underactive bladder: clinical features, urodynamic parameters, and treatment. Int Neurourol J 2015;19:185-9. 
6. Foditsch EE, Roider K, Patras I, Hutu I, Bauer S, Janetschek G, et al. Structural changes of the urinary bladder after chronic complete spinal cord injury in minipigs. Int Neurourol J 2017;21:12-19.

7. Hattori T, Lluel P, Rouget C, Rekik M, Yoshiyama M. Ketanserin and naftopidil enhance the potentiating effect of alpha-methyl-serotonin on the neutrally-induced contraction of human isolated urinary bladder muscle strips. Int Neurourol J 2017;21:20-28.

8. Kim SJ, Shin IS, Eun SJ, Whangbo TK, Kim JW, Cho YS, et al. Evidence is enough?: a systematic review and network meta-analysis of the efficacy of tamsulosin $0.2 \mathrm{mg}$ and tamsulosin $0.4 \mathrm{mg}$ as an initial therapeutic dose in Asian benign prostatic hyperplasia patients. Int Neurourol J 2017;21:29-37.

9. Dunn CJ, Matheson A, Faulds DM. Tamsulosin: a review of its pharmacology and therapeutic efficacy in the management of lower urinary tract symptoms. Drugs Aging 2002;19:135-61.

10. Kawabe K, Ueno A, Takimoto Y, Aso Y, Kato H. Use of an alpha 1-blocker, YM617, in the treatment of benign prostatic hypertrophy. YM617 Clinical Study Group. J Urol 1990;144:908-11.
11. Shim SR, Kim JH, Choi H, Lee WJ, Kim HJ, Bae MY, et al. General effect of low-dose tamsulosin $(0.2 \mathrm{mg})$ as a first-line treatment for lower urinary tract symptoms associated with benign prostatic hyperplasia: a systematic review and meta-analysis. Curr Med Res Opin 2015;31:353-65.

12. Park CH, Chang HS, Oh BR, Kim HJ, Sul CK, Chung SK, et al. Efficacy of low-dose tamsulosin on lower urinary tract symptoms suggestive of benign prostatic hyperplasia : a nonblind multicentre korean study. Clin Drug Investig 2004;24:41-7.

13. Kim SW, Lee WC, Kim MT, Ko K, Lee WK, Lee CH, et al. Effects of low-dose tamsulosin on sexual function in patients with lower urinary tract symptoms suggestive of benign prostatic hyperplasia. Korean J Urol 2013;54:697-702.

14. Kim KS, Kim JH, Lee SH, Ha US, Han DH, Chang IH, et al. Efficacy of dose escalation of tamsulosin for the treatment in symptomatic benign prostatic hyperplasia of lower urinary tract symptoms: a randomised, double-blind, phase 3 trial in Korean men [abstract]. J Urol 2016;195(4 Suppl):e466. Abstract No. PD22-12. 